\title{
A Conceptual Model for Product Service System (PSS)
}

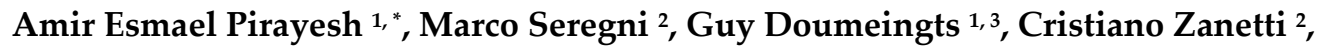 \\ Ingo Westphal ${ }^{4}$ and Carl Hans ${ }^{5}$ \\ 1 INTEROP-VLab, c/o Bureau Aquitaine Europe, 21 rue Montoyer, 1000 Brussels, Belgium; Operational Office: \\ A31 building, 351 Cours de la Libération, 33405 Talence, France; amir.pirayesh@interop-vlab.eu (A. P.); \\ guy.doumeingts@interop-vlab.eu (G. D.) \\ 2 Politecnico di Milano, Department of Management, Economics and Industrial Engineering, Via \\ Lambruschini 4/b, 20133 Milano, Italy; marco.seregni@polimi.it (M. S.); cristiano.zanetti@polimi.it (C. Z.) \\ 3 Laboratory IMS CNRS Production Engineering Group, 351 Cours de la Libération, 33405 Talence, France; \\ 4 BIBA, Bremer Institut für Produktion und Logistik GmbH, Hochschulring 20, D-28359 Bremen, Germany; \\ win@biba.uni-bremen.de; win@biba.uni-bremen.de \\ 5 FTI Engineering Network GmbH, Schmiedestrasse 2,15745 Wildau, Germany; carl.hans@ingenieurbuero- \\ hans.de \\ * Correspondence: amir.pirayesh@interop-vlab.eu; Tel.: +33-5-4000-3654
}

\begin{abstract}
Servitization or productization, indicating evolution from product to service economy or vice-versa, can be considered as a successful strategy to gain competitiveness based on novel combination of products and services. To decrease the risks of servitization and to support the sustainable development of its main outcome, being Product Service System (PSS), it is required not only to have a clear and common understanding of the core business and processes but also to share the same definitions on (PSS) concepts as the main outcome of servitization. For this purpose, managers could be supported by abstract models with a limited number and high ratio of known concepts in the early stages of PSS development. Through an extensive literature review on this subject, followed by a structured conceptualization approach and discussions with domain experts, this paper proposes a Conceptual Model (PSS-CM). To validate the results, PSS-CM and its elements were discussed in several iterations, from both academic and industrial points of view, in the frame of a European research project. In the frame of this project, a case study was also performed to illustrate the instantiation of PSS-CM.
\end{abstract}

Keywords: product service system (pss); servitization; productization; conceptual model; conceptualization; enterprise management; strategic change,

\section{Introduction}

Considering the business environment of manufacturing enterprises in the recent decades, moving from product economy to service has become a practical strategy to achieve competitiveness $[1,2]$. This movement, called Servitization [of business], is defined as "the evolutionary path of the business model of a manufacturing company from a pure product perspective towards an integrated product-service orientation is usually termed as Servitization of manufacturing" [3]. The evolution of research on this subject is studied in [4].

Servitization, leads to the design and development of Product Service Systems (PSS) where innovative combinations of products and services are realized to increase the market share [5-7]. PSS can be also designed, from service to product (i.e. productization) when the enterprise of origin is a service provider. Such movement is mentioned in [8]. The concept of PSS has emerged as one of the most important business concepts for industrial organizations [9]. The core components of this concept are product, service and system [10].

One of the main challenges ahead of servitization is the complexity of PSS. From a generic perspective, a system, can become complex due to the multiplicity of the components (i.e. social, technical, economic or organizational) and their heterogeneity. This has been mentioned, for a long 
time, as a challenge in the development and analysis of the production systems [11,12]. A PSS not only inherits the complexity of production system, but is also involved with service related elements interacting with that system [13]. Therefore, even though servitization is stated as a reasonable strategy, it is not always easy to adopt [1]. Dealing with such strategical matters [14], managers should be more and more supported to be flawless in their managerial actions, strategic decisions, and global orientation of resource allocations and investments [15]. To support enterprise management in the servitization process, generally, modeling techniques can be applied to provide a representation of the systems under analysis and to increase the knowledge on the new concepts [16]. In addition, such techniques can bring a common view to different actors, all along the PSS lifecycle. Therefore, the initial research question is "how to support enterprise management in the servitization / productization process with a sound modelling approach?"

Idrissi et al. analyzed several modeling approaches supporting PSS design based on the genericity, standardization, and detail level of the approaches [17]. However, these issues could be less critical in the early stages of servitization, such as strategic planning $[7,14]$, or in the conceptual design (the scope of this research work). In these stages, servitization is still under strategical analysis by managers or PSS ideas have not yet become design concepts. In fact, too much detail, excessive number of new concepts or new terminology representing known concepts, might make the modeling approach difficult to adopt by the user. It could also lead to complex results (i.e. complex PSS models), which is against the initial objective of modeling. Therefore, the previously mentioned research question can be formulated as "how to support enterprise management in the early stages of servitization / productization with adapted conceptual models?" which is addressed in this research work.

\section{Methodology}

\subsection{Research methodolgy}

Following the methodology illustrated in Figure 1, this research work intends to contribute to the above question by proposing a PSS Conceptual Model (PSS-CM), resulted from a structured conceptualization. Knowing the profile of the potential users, the objective of elaborating a conceptualization approach was to achieve $\mathrm{CM}$, with high probability of adoption, by decreasing the ratio of new concepts, necessary for understanding a PSS and its development process, of the known concepts. For this purpose, PSS was first studied as a generic system. This provided the possibility to design the initial structure (core) of the PSS-CM. This was followed by the extension of the core in two layers based on the analysis of PSS definitions, classifications, and viewpoints, proposed in the literature. Having defined the conceptualization approach, identification of the concepts was started by the analysis of PSS (1) definitions, (2) classifications, and (3) viewpoints.

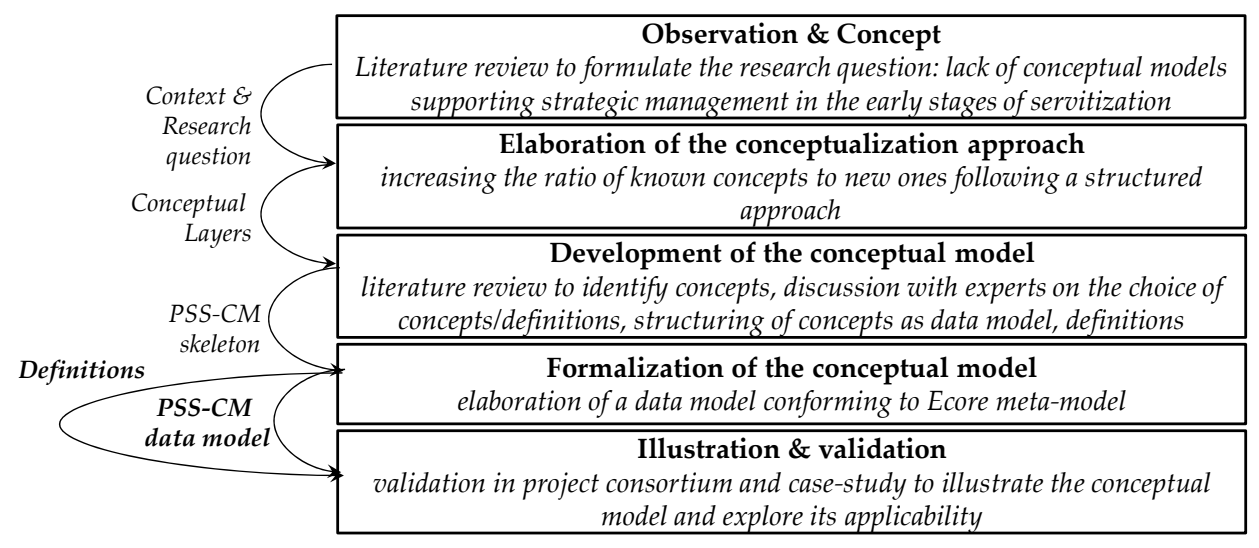

Figure 1. Research methodology

The identified concepts, and their properties, were synthetized and structured to design the skeleton of the PSS-CM. It was accompanied with detailed definition of its elements. PSS-CM was 
also developed as a data model, with known meta-model, to facilitate its adoption and instantiation. Eventually, to study and illustrate the applicability of the PSS-CM, it was applied in an industrial use-case using enterprise data. The main objective was to support the servitization process undertaken by the enterprise, by highlighting of key PSS concepts and definitions.

\subsection{Conceptualization approach}

For the purpose of designing a generic and abstract model for PSS, a conceptualization approach is proposed. This approach is based on the collection and analysis of PSS related concepts in the following steps (see Figure 2):

1. Configuration of a PSS as a system (Core): the PSS is first analyzed from a systemic point of view while focusing on the structure, characteristics and components that are intrinsic for a system. This allows defining the core of the PSS conceptual model.

2. Specification of system concepts in PSS context: In this step, the concepts identified in the previous step are specified and extended based on the characteristics of PSS. This was done according to:

a. $\quad$ PSS as a dichotomy (1st layer): concepts were studied in two parts; product related concepts (i.e. product and production system), and service related concepts (service and service system).

b. PSS as a whole (2nd layer): definitions, classifications and viewpoints addressing PSS as a whole were studied.

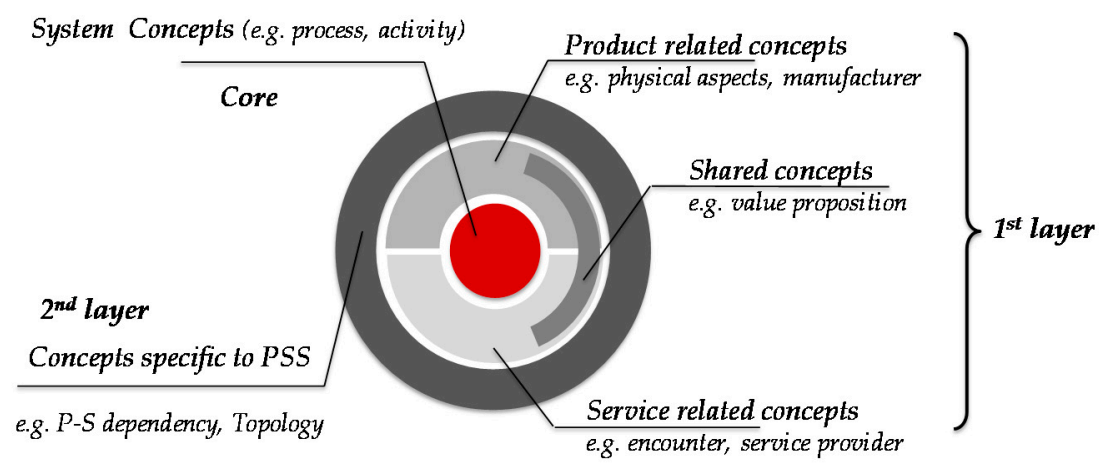

Figure 2. PSS conceptualization approach

\section{Literature review}

\subsection{PSS modeling and conceptualization}

Lee et al. defines conceptualization as the extraction of vocabularies from a domain or providing a simplified view of the world [domain] we wish to represent [18]. During this task, concepts and conceptual relationships are created as conceptual models [19] which are the basis for structuring the knowledge of that given domain [20].

In PSS context, Annarelli et al. provided a conceptual structure depicting the current situation of literature dealing with the analysis of economic impact and environmental/social impact of PSS [21]. From a business model perspective, a conceptual framework to assist with the development of PSS has been proposed in [22].

Model Driven Service Engineering Architecture (MDSEA), developed in the frame of a European research project in servitization context, can be also mentioned [23]. This architecture, including a methodology, proposes the usage of modeling languages at different levels (from business to technological) and from different perspectives (human/organizational resources, physical means and ICT supports). 
121

122

123

124

125

126

127

128

The common result of conceptualization approaches, the conceptual model, can be formalized, extended and made graphical to be used in modeling approaches to represent an object in an abstract way. In PSS context, some modeling approaches supporting PSS design were recently studied in [17]. Here, we extended, the analysis of Idrissi et al., with some additional modeling approaches covering other stages of PSS lifecycle (see Table 1). It should be mentioned that, this extended analysis highlighted the lack of approaches with strategical purpose supporting enterprise managers who plan and control the servitization and PSS development process.

Table 1. PSS modeling approaches (inspired by [17])

\begin{tabular}{|c|c|c|c|c|}
\hline Reference & Year & Approach & Summary & Lifecycle focus \\
\hline $\begin{array}{l}{[24]} \\
{[25]}\end{array}$ & $\begin{array}{l}2006 \\
2010\end{array}$ & Integrated Life Cycle & $\begin{array}{l}\text { A modeling technique based on service lifecycle } \\
\text { (integrating product lifecycle) }\end{array}$ & $\begin{array}{l}\text { Lifecycle } \\
\text { management }\end{array}$ \\
\hline $\begin{array}{l}{[26]} \\
{[27]}\end{array}$ & $\begin{array}{l}2007 \\
2009\end{array}$ & $\begin{array}{l}\text { Service Engineering } \\
\text { Service Explorer }\end{array}$ & $\begin{array}{l}\text { Multi-model framework for PSS design } \\
\text { Computer-aided service design }\end{array}$ & PSS design \\
\hline [28] & 2008 & $\begin{array}{l}\text { Service-Oriented Modeling } \\
\text { Framework (SOMF) }\end{array}$ & $\begin{array}{l}\text { Service-oriented life cycle modeling methodology } \\
\text { based on the service-oriented modeling paradigm }\end{array}$ & $\begin{array}{l}\text { Lifecycle } \\
\text { management }\end{array}$ \\
\hline [29] & 2009 & IPS2 Metadata Model & $\begin{array}{l}\text { A metadata reference model for Industrial PSS } \\
\left(\mathrm{IPS}^{2}\right) \text { lifecycle management }\end{array}$ & $\begin{array}{l}\text { Lifecycle } \\
\text { management }\end{array}$ \\
\hline $\begin{array}{l}{[30]} \\
{[31]}\end{array}$ & $\begin{array}{l}2009 \\
2011\end{array}$ & $\begin{array}{l}\text { Extended/Product Service } \\
\text { Blueprint }\end{array}$ & $\begin{array}{l}\text { Enlargement of the classical modeling technique } \\
\text { "Service Blueprint" }\end{array}$ & P-S Integration \\
\hline$[32]$ & 2010 & PSS Layer Method & $\begin{array}{l}\text { Multi-layer modeling framework to highlight } \\
\text { requirements and tasks for PSS design }\end{array}$ & $\begin{array}{l}\text { PSS design } \\
\text { (Requirements } \\
\text { elicitation) }\end{array}$ \\
\hline$[33]$ & 2009 & $\begin{array}{l}\text { SLM (Service Modeling } \\
\text { Language) and SML } \\
\text { Interchange Format (SML-IF) }\end{array}$ & $\begin{array}{l}\text { Constructs for creating models of complex } \\
\text { services and systems, and standard for } \\
\text { exchanging service models }\end{array}$ & $\begin{array}{l}\text { PSS design } \\
\text { (process } \\
\text { modeling) }\end{array}$ \\
\hline [34] & 2013 & $\begin{array}{l}\text { Functional Hierarchy } \\
\text { Modeling }\end{array}$ & $\begin{array}{l}\text { Modeling technique for PSS functions. } \\
\text { Proposition of a novel PSS typology }\end{array}$ & $\begin{array}{l}\text { PSS design } \\
\text { (Functional } \\
\text { analysis) }\end{array}$ \\
\hline [23] & 2014 & $\begin{array}{l}\text { Model Driven Service } \\
\text { Engineering Architecture } \\
\text { (MDSEA) }\end{array}$ & $\begin{array}{l}\text { Multi-level architecture and methodology for } \\
\text { service system design and development }\end{array}$ & $\begin{array}{l}\text { PSS design and } \\
\text { development }\end{array}$ \\
\hline [35] & 2014 & $\begin{array}{l}\text { Extended Product Business } \\
\text { Model }\end{array}$ & $\begin{array}{l}\text { Methodology to integrate Extended Product (EP) } \\
\text { into the business models }\end{array}$ & $\begin{array}{l}\text { Business } \\
\text { Modeling }\end{array}$ \\
\hline$[36]$ & 2016 & $\begin{array}{l}\text { PSS Multi-Views Modeling } \\
\text { Framework }\end{array}$ & $\begin{array}{l}\text { A multi-view modeling framework combining } \\
\text { product-oriented and service-oriented } \\
\text { engineering. }\end{array}$ & PSS design \\
\hline [21] & 2016 & PSS conceptual structure & $\begin{array}{l}\text { A conceptual structure depicting the situation of } \\
\text { literature dealing with the analysis of economic, } \\
\text { environmental, and social impact of PSS }\end{array}$ & PSS evaluation \\
\hline [22] & 2017 & $\begin{array}{l}\text { PSS business model conceptual } \\
\text { framework }\end{array}$ & $\begin{array}{l}\text { A conceptual framework to support PSS } \\
\text { development from business model perspective }\end{array}$ & Business Model \\
\hline
\end{tabular}

\section{0}

131

132

133

134

135

136

\subsection{PSS as a system}

In the first step of conceptualization, the PSS concept is studied while focusing on the term system. The System Thinking is the result of the research works done by many authors among which we can refer to System Theory [37], Management Decision [38], and Theory of Hierarchical Multilevel Systems [39]. The idea behind these research works is that the same concepts (System theory concepts) can be applicable in various disciplines (i.e. biology, physics, economy, organization, computer sciences, and cybernetics) when referring to the term system.

Based on the above theories, GRAI (Graphs with Results and Actions Inter-related) model decomposes a manufacturing/service system or particularly an enterprise system into three subsystems and proposed specific modeling techniques for each subsystem [40,41]. A brief description of these subsystems is given below (see Figure 3):

1. The controlled subsystem (also called physical subsystem) transforms the inputs (materials and information) into outputs (new information, products or services) to be mainly delivered to the customers. In this subsystem, the main concepts are process, activity, resource and physical entities (materials, tools, machines, etc.). 
145

146

147

148

149

150

151

2. The control subsystem (also called decisional subsystem) manages the physical subsystem based on the objectives of the global system (e.g. enterprise system) and the feedback to deliver actions or adjustments. In this subsystem, the main concepts are decider, decision and performance indicator.

3. The information subsystem includes information from the physical sub-system and from the customers, suppliers and other stakeholders (external environment). In this subsystem, the main concepts are data, information, and communication.

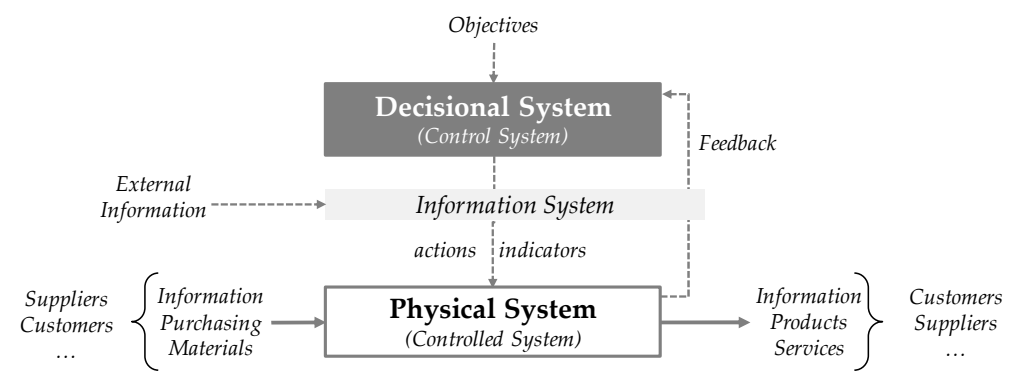

Figure 3. key system concepts (adapted from GRAI Model $[40,41]$ )

\subsection{PSS as a dichotomy}

In this step, PSS was analyzed as a dichotomy of product-related and service related concepts. Among the definitions proposed in the state of the art, the ones proposed in the context of Servitization are highlighted.

\subsubsection{Product related concepts}

Quality Management (QM) standard (DIN ISO EN 9000:2005, revised by ISO 9000:2015), representing an engineering perspective, defines a product as the result of a process [42]. This process is the manufacturing process in which materials, also called work pieces, become a product [43]. The manufacturing process, which is necessarily part of a business process, represents the customer needs [44] with the objective of adding value to the product $[45,46]$. The product is the outcome of a Production System which also delivers it to the customer. This system is composed of various components: materials, machine, people, organization, software, hardware [47]. Depending on its defined perimeter, a production system could be an enterprise, a part of an enterprise (workshop, manufacturing unit) or a set of enterprises (production network).

In servitization context, according to Tukker, a Product is a tangible commodity manufactured to be sold, fulfilling user's needs [10]. "A Product is sold to a customer and is generally considered as a tangible physical entity. In Servitization, a product is related to one or a set of services in a virtual enterprise and ecosystem" [47]. To distinguish the product from service, Callon et al. puts the focus on the notion of goods [48]: "a good implies a stabilization of characteristics at the moment an entity, product or service is ready to be traded. A product is an economic good that can be seen from a variety of perspectives: production, circulation and use thus a product corresponds to a process, a trajectory in time, whereas a good corresponds to a state at a point in time".

\subsubsection{Service related concepts}

According to Tukker, a service is an activity done for the stakeholders with intangible results and economic value [10]. The service is in fact the outcome of a Service System which consists of people and technologies that adaptively compute the knowledge about changing values in the system and adjust to it accordingly [49]. A service system is composed of various elements: product, machine, people, organization, IT tools and customer. Considering the last one, MSEE project indicates that it is impossible to produce a service if the customer is not involved in the loop and data-informationknowledge is constantly shared between producer and consumer. MSEE also emphasizes on the delivery of the service in a Service System. 
Spohrer et al. define Service and Service System as [50]: "Service is the application of competence for the benefit of another. So service involves at least two entities, one applying competence and another integrating the applied competences with other resources and determining benefit (value co-creation). We call these interacting entities service systems";

\subsection{PSS as a whole}

PSS concept can be also defined, classified or viewed as a whole, instead of two separate sets of product and service related concepts. This highlights the specific concepts necessary for representing the association, interaction and integration of these concept sets.

\subsubsection{Definitions}

In the recent study of Oliveira et al., a comprehensive bibliometric analysis of the PSS research field is performed which provides an understanding on this domain [9]. The PSS definition proposed by the top five papers regarding citation are studied here in addition to the definition proposed by [51], as a more recent paper addressing PSS from industrial perspective, and by MSEE [47] and SusProNet [56], which are outstanding examples of European research projects and networks in servitization context.

According to Goedkoop et al. "a PSS is a marketable set of products and services capable of jointly fulfilling a user's need. The PS System is provided by either a single company or by an alliance of companies. It can enclose products (or just one) plus additional services. It can enclose a service plus an additional product. A product and service can be equally important for the function fulfilment." [52]. The authors also describe key-factors of success for PSS [52]; creating value for clients, by adding quality and comfort, customizing offers or the delivery of the offer to clients, creating new functions or making smart or unique combinations of functions; decreasing the threshold of a large initial or total investment sum by sharing, leasing, and hiring, decreasing environmental load (often this will bring additional and perceived Eco-benefits), and increasing the quality of contacts with clients.

Mont defines a PSS as a "System of products, services, supporting networks and infrastructure that is designed to be: competitive, satisfy customer needs and have a lower environmental impact than traditional business models" [53].

PSS is defined by Manzini \& Vezzoli as "an innovation strategy, shifting the business focus from designing (and selling) physical products only, to designing (and selling) a system of products and services which are jointly capable of fulfilling specific client demands" [54].

Tukker considers PSS as a system consisting of tangible products and intangible services designed and combined so that they are jointly capable of fulfilling specific customer needs. The key elements of a PSS are: The Product (a tangible commodity manufactured to be sold, fulfilling user's needs), the Service (an activity done for the stakeholders with an economic value, with intangible results ...), and the System (a collection of elements and their relations referring to the system of products and services delivered to the customer and the system of actors involved) [10].

As stated by Baines et al., "A PSS is an integrated product and service offering that delivers value in use. A PSS offers the opportunity to decouple economic success from material consumption and hence reduces the environmental impact of economic activity. The PSS logic is premised on utilizing the knowledge of the designer-manufacturer to both increase value as an output and decrease material and other costs as an input to a system" [55].

The PSS definition proposed in MSEE project is: "a collection of interrelated components that are organized for a product service related purpose, i.e. to design, to produce, to manage and to deliver product services to customers. A PSS consists of any combination of resources belonging to three domains: IT domain, Organization/Human domain (including management and organization), and Physical Means domain (including machine, robot and any other material handling devices)" [47]. 
In SusProNet project (Product Services in the application area "Information and Communication"), the following definitions are proposed [56]: 1) A product service is defined as a value proposition that consists of a mix of tangible products and intangible services designed and combined so that they are jointly capable of fulfilling integrated, final customer needs. 2) A ProductService System (PSS) is defined as the product-service including the network and infrastructure needed to 'produce' a product-service.

According to Andersen et al., a "Product/Service-System is an innovation strategy, where a greater integration of products and services has the potential to decouple business success and economic growth from mere product sales." [51]:

- "PSS solution does not necessarily imply that the service provider is the producer of the physical product(s) included in the PSS, but the service provider must take responsibility for the delivery of the service to the customer."

- “... benefits of PSS originate from one important characteristic: namely, the ability of a PSS approach to identify inefficiencies in inter-/intra-organizational relations and provide holistically minded business models, addressing the identified shortcomings."

Considering the above definitions, the following points can be highlighted (see Table 2):

- Economic activity [10, 52-54]: PSS is related to an economic activity with known market, business model, selling point and economic value A PSS is business oriented and there is a customer willing to pay for the P-S and participating in the business model. PSS separates business success and economic growth from mere product sales. PSS is designed, combined and provided to the customer to fulfil its needs with higher value proposition comparing to isolated products and services [10,47,52,54-56]. Therefore, the benefits of the PSS for the customer comparing to mere products or services should be clearly defined. Sometimes the service contributes/forms the major part of the provided value.

- Interconnected Product and Services [10,47,52,54-57]: The outcome of a PSS is a mix of tangible products and intangible services which should interact jointly. In a PSS the service is not necessarily an "add-on" to the product since product and service can form an integrated solution including entities with different relative importance.

- Organizational aspects [47,52,53,55,56]: Configuration and type of internal and external resources are important issues in PSS. Different types of supports should be combined on product and service lifecycles. PSS is usually developed within a network of enterprises due to the necessity of the involvement of stakeholders with diverse competences and functions. It also requires an infrastructure supporting product usage and service delivery.

- Sustainability [53,55]: The environmental impacts of PSS are usually lower than traditional business models, e.g. when a service supports the sharing of the physical products such as vehicles. In fact, Servitization might decrease the usage of resources and consequently the negative manufacturing impacts on the environment. Annarelli et al. provided a conceptual structure, depicting the current situation of literature dealing with the analysis of PSS [21].

Table 2. Synthesis of PSS definitions

\begin{tabular}{ccccccc}
\hline \multirow{2}{*}{ Reference } & Year & \multicolumn{5}{c}{ Highlights } \\
\cline { 3 - 7 } & & Economic Activity & Interaction \& Integration & Value proposition & Organizational aspects & Sustainability \\
\hline$[52]$ & 1999 & Marketable & Jointly fulfilling & User's need & A company/alliance & - \\
{$[53]$} & 2002 & Business models & - & - & Networks, infrastructure Environmental impact \\
{$[54]$} & 2003 & Selling & Jointly fulfilling & Client demands & - & - \\
{$[10]$} & 2004 & Economic value & Jointly fulfilling & Customer need & & - \\
{$[55]$} & 2007 & - & Integrated offering & Value in use & Knowledge, expert & Environmental impact \\
{$[56]$} & 2004 & - & Jointly fulfilling & Value proposition & Network, infrastructure & - \\
{$[47]$} & 2012 & - & Interrelated components & Customers & Resource combination & - \\
\hline
\end{tabular}




\subsubsection{Classifications}

In the second step of conceptualization, various classifications of PSS proposed in the literature were studied. These classifications are summarized in Table 3. While initial approaches were product-centered, in the course of time the services became a more important and self-reliant part of the product-service combination. In some cases, the physical product was even aligned to a service or parts of it were replaced by services, e.g. cloud services that replace hardware storage capacity. This development led to enhanced value propositions for the customer and to better options for differentiation in comparison with competitors.

Table 3. Synthesis of PSS classifications

\begin{tabular}{ccl}
\hline Reference & Year & \multicolumn{1}{c}{ Dimension } \\
\hline$[57]$ & 2000 & Contribute to sustainability \\
{$[58]$} & 2001 & Evolution of Product Service Systems, Value proposition \\
{$[10]$} & 2004 & Product ownership, Provider's role in the value production, Business Model \\
{$[59]$} & 2011 & Product and service engineering, \\
{$[60]$} & 2012 & Relationship between products and services (duality vs. unity), Products Ownership, Role Technology \\
{$[34]$} & 2013 & Level of integration and performance orientation of the dominant revenue mechanism within the PSS \\
{$[61]$} & 2016 & Product type (Durable vs Capital goods), Service type \\
\hline
\end{tabular}

\subsubsection{Viewpoints}

A viewpoint indicates from which aspect or with which focus a subject is or should be addressed. According to [4], research on PSS can be studied through different lenses such as value co-creation and collaboration; systems and networks; information and communications technology; and complexity.

Some PSS viewpoints can be identified in conceptual frameworks. Such a framework is proposed in the frame of the research project which is the origin of the present research work [63]. In the proposed PSS conceptual framework, each viewpoint is represented as a layered dimension where the highest maturity level is the symbiosis of product and service related entities. These dimensions are mentioned in the followings.

Business Model (BM): under this viewpoint, PSS can be studied as an economic exchange which creates value as its core purpose and central process [64]. The enterprises must be able to clearly define the actual product or service and their value proposition for the customer. Business Model is a confirmed viewpoint and issue in PSS context $[35,65]$. Its actual relevance is partially expressed by [66]. From this viewpoint, a conceptual framework to assist with the development of PSS has been proposed in [22].

Innovation Openness: PSS is studied under this viewpoint as an innovating process with multiple actors and objectives. In this complex ecosystem, the following misunderstanding can occur: "Who's responsible for what when things fail [during or after the PSS development]? [As a trigger of innovation] It is very costly to solve all the problems of responsibilities when things fail" [8]. Therefore, focus here is on responsibilities within PSS ecosystem and openness of innovation process towards external actors [49].

Dependency: this viewpoint focuses on functionalities and interactions provided by each component within a PSS. Service design should cope with the functionalities provided by the product coupled with that service, and vice versa [65]. In addition to this functional interdependency, PSS concept envisions several interactions in both directions all along the lifecycle [67]. Such interactions have been studied and visualized by $[68,69]$.

Topology: Under this perspective, a PSS consists in a combination of cyber ("Digital world") and physical ("Real world") elements. Therefore, PSS typologies differ in terms of degree of digitalization. 
For instance, a PSS might adopt "Cyber-Physical Production Systems (CPPS)" to foster new processes and production methods for reducing "time to market", waste and failures, as well as improving quality and cost effectiveness." [70].

Interoperability: During PSS engineering, service and product staff, with various fields of expertise or with different types of resources, must exchange information. For instance, in the case of the maintenance service, product design requires the knowledge of the maintenance operator, gained from his experiences, to improve the design of the product [67]. Therefore, these actors should be interoperable (i.e. capable of exchanging information and semantically understand each other). In this case, solutions, in the form of collaboration tools or interoperability improvement methods, are required [71].

Modeling $\mathcal{E}$ simulation (MES): As mentioned in the introduction, PSS is usually a complex system due to the variety of its elements with heterogeneous nature related to both production and service domains. In such a complex environment, modeling can support the understanding of the structure and behavior of a PSS. Pirayesh et al. propose a unified decisional model to support the PSS lifecycle management [13]. Modelling can also facilitate the development of a PSS. Model Driven Service Engineering has been addressed in [23] while proposing an architecture and methodology for this purpose. As a complementary task after modeling, simulation can be necessary for providing assessments of the system performance and behavior in addition to static abstractions of the system [16]. A platform offering new approaches to visualize, simulate and test services are discussed in [72].

\section{PSS Conceptual Model}

The conceptualization approach mentioned in the methodology section guided the identification of the main concepts required for describing and understanding a PSS in an abstract way. These concepts and their properties formed the skeleton of PSS Conceptual Model (PSS-CM). They are represented in different ways (i.e. classes, attributes, associations and cardinalities, and enumerations) in a class diagram according to their conceptual level and role (see Figure 4). To provide a formalized model, PSS-CM is developed as a meta-model in accordance to Ecore in Eclipse modeling environment [73].

Definitions are proposed in the following paragraphs for the key elements (i.e. classes and attributes) of PSS-CM. Other elements such as associations and cardinalities are described in Table A1 of Appendix A. To perform a preliminary validation, the elements and definitions were discussed in several iterations both from scientific and industrial point of view in the frame of the aforementioned European research project (PSYMBIOSYS) while considering the literature review. It should be mentioned that some examples of these elements are provided within the case-study sections.

First, a global definition is proposed for PSS: it is a system including a mix of tangible products and intangible services designed, combined and provided to the customer so that they jointly and symbiotically can fulfill specific customer needs with higher added values comparing to isolated products and services. This definition can be extended using the PSS-CM.

Ecosystem [class]: A PSS is usually related to an Ecosystem [class]. It consists of all actors who play an active role around one or several P-S. The involvement of these actors in the PSS innovation or development process can be different according to the openness of this process. In fact, among the potential actors, the ecosystem is created according to the enterprise business rules (e.g. collaboration policy) and the characteristics of each actor. In an enterprise, the early steps (i.e. strategy analysis, market analysis, etc.) of servitization are usually managed and performed by the enterprise management (at strategical level) and its engineering team created in the beginning of the servitization. The next steps might require the inclusion of other actors; internal (e.g. management at different levels, design experts, technical specialists, marketing, sales people ...) and external (e.g. suppliers, customers, domain experts, as well as potentially the general public, Research and Technology Organizations (RTOs), Digital Innovation Hubs (DIHs), Competence Centers etc. 


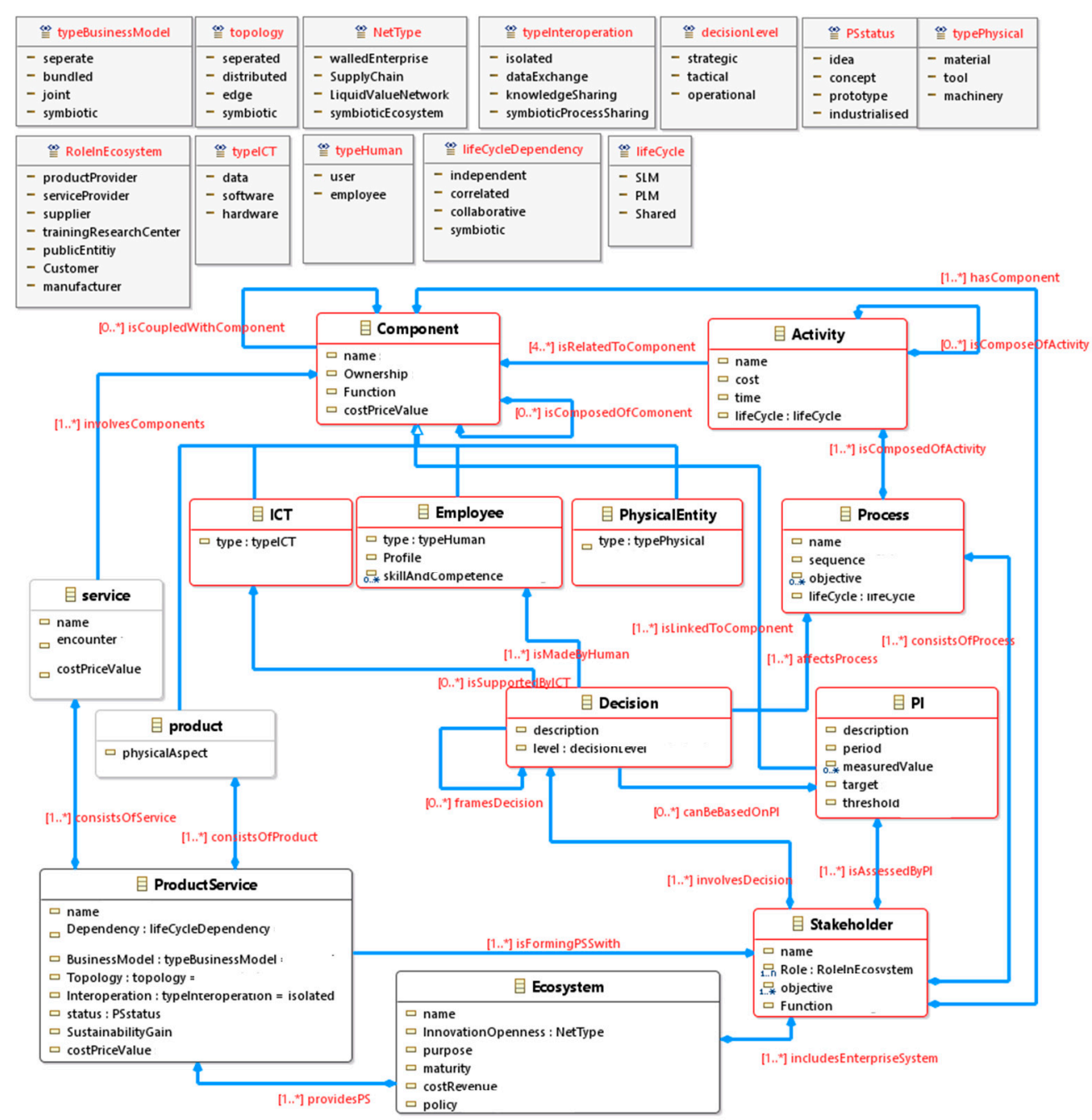

Figure 4. PSS Conceptual Model (PSS-CM)

In PSS-CM, the Ecosystem class is considered to be the root since it is the broader concept and it is related with all the other entities. To complete the definition of PSS ecosystem, some key attributes are proposed (see Table 4 ).

Table 4. Ecosystem attributes

\begin{tabular}{ll}
\hline Attribute & Description \\
\hline \multirow{3}{*}{ InnovationOpenness } & The degree of involvement of different stakeholders in the innovation process. It can be: (1) \\
& $\begin{array}{l}\text { Walled Enterprise, (2) Extended Supply Chain, (3) Liquid Value Network or (4) Symbiotic } \\
\text { Ecosystem. }\end{array}$ \\
purpose & The objective behind the formation of the ecosystem. \\
$\begin{array}{l}\text { Policy } \\
\text { maturity }\end{array}$ & $\begin{array}{l}\text { The set of rules for regulating collaborations among stakeholders in the ecosystem. } \\
\text { History of the collaboration between stakeholders within the ecosystem. } \\
\text { cost/Revenue }\end{array}$ \\
\hline
\end{tabular}

Stakeholder [class]: Once the ecosystem is created and the servitization/productization is a confirmed strategy, the involved actors (e.g. persons, enterprises or organizations such as research centers, universities, public bodies, etc.) for realizing this strategy become the Stakeholders [class]. Stakeholders manage or perform processes which are supported by resources. To complete the definition of stakeholder, the following key attributes can be mentioned (see Table 5).

1 Attributes' type (e.g. string) have been removed from the model. 
Table 5. Stakeholder attributes

\begin{tabular}{|c|c|}
\hline Attribute & Description \\
\hline role(s) & $\begin{array}{l}\text { The role of the stakeholder within the P-S ecosystem, which reflects its nature to some extents. } \\
\text { Roles can be: (1) product provider, (2) service provider, (3) supplier, (4) training / research center } \\
\text { and (5) public entity, (6) customer or (7) manufacturer. }\end{array}$ \\
\hline objective(s) & $\begin{array}{l}\text { Expectation and desired evolution for the global performance of the stakeholder. The objectives, } \\
\text { at this level, results from the aggregation of process-specific goals. }\end{array}$ \\
\hline etc. & Other attributes according to the specific needs (e.g. Strategy, Legal form, Finance, etc.). \\
\hline
\end{tabular}

Table 7. Service attributes

\begin{tabular}{ll}
\hline Attribute & Description \\
\hline encounter & $\begin{array}{l}\text { Short-term transactional interaction involving on one hand, a provider who delivers the Service, } \\
\text { and on the other hand a user. Delivery method is also addressed here. }\end{array}$ \\
costPriceValue & Service cost, price or its value for the customer. \\
\hline
\end{tabular}

ProductService [class]: It represents the [expected] output provided by the PSS ecosystem (or a part of it) to the final customer/user who himself is a stakeholder closely involved in PSS lifecycle. It consists of a mix of tangible products and intangible services with a specific association. The following key attributes can be considered for this class (see Table 8).

Table 8. ProductService attributes

\begin{tabular}{ll}
\hline Attribute & Description \\
\hline lifeCycleDependency & The links between the P and S related activities all along P-S life-cycles (e.g. resource allocation). \\
& It can be: (1) independent, (2) correlated, (3) collaborative or (4) symbiotic. \\
TypeBusinessModel & $\begin{array}{l}\text { The business relation between the product and service (e.g. type of value proposition, channels, } \\
\text { resources, etc.). It can be: (1) separated, (2) bundled, (3) joint or (4) Symbiotic. }\end{array}$ \\
costPriceValue & A product-service has a cost and a price (not always the sum of product and service costs). \\
Topology & The configuration of cyber and physical part of a P-S. It can be: (1) Separated Cyber-Physical, (2) \\
& Distributed Cyber-Physical, (3) Edge Cyber-Physical or (4) Symbiotic Cyber-Physical. \\
Interoperation & The level of exchanges between the product and service systems in terms of data, knowledge and \\
status & processes. It can be: (1) Isolated, (2) Data Exchange, (3) Knowledge Sharing or (4) Symbiotic. \\
SustainabilityGain & The development stage of a P-S. It can be: (1) Idea, (2) Concept, (3) Prototype or (4) Industrialized. \\
& The reduction in environmental impacts thanks to the novel combination of products and services. \\
\hline
\end{tabular}

Process [class]: It is a structured set of activities into which an enterprise system can be decomposed. Examples of process can be design, planning, production, quality check; delivery, etc. The definition of process can be completed with the following attributes (see Table 9).

Table 9. Process attributes

\begin{tabular}{ll}
\hline Attribute & Description \\
\hline $\begin{array}{l}\text { sequence } \\
\text { objective }\end{array}$ & The chronological and/or logical order of activities forming the process. \\
Expectation and desired evolution for performances at process level. \\
lifecycle & $\begin{array}{l}\text { The lifecycle(s) which includes the process. It can be: (1) PLM, (2) SLM or (3) shared (in case of a } \\
\text { process belonging to both Product and Service Lifecyle). }\end{array}$ \\
\hline
\end{tabular}


Activity [class]: It represents a sub-step of a process which transforms inputs into outputs by means of different types of resource and under the control of different mechanisms. Activities can be shared between the processes. To complete the definition of an activity, the following key attributes are proposed (see Table 10).

Table 10. Activity attributes

\begin{tabular}{ll}
\hline Attribute & Description \\
\hline cost & $\begin{array}{l}\text { Total cost of carrying out the activity for the company in a predefined unit of time } \\
\text { (minute/hour/day). }\end{array}$ \\
Overall time required for completing the activity (minute/hour/day/week) for a unit of output. \\
lifecycle & $\begin{array}{l}\text { The lifecycle(s) which includes the activity. It can be: (1) PLM, (2) SLM or (3) Shared (in case of an } \\
\text { activity belonging to both Product and Service Lifecycles). }\end{array}$ \\
\hline
\end{tabular}

ComponentResource [class]: It represents an entity of different nature playing a role in an activity within the enterprise system. Some components are part of the Product-Service bundle while others are involved in the decisions. Some components are owned by the enterprise (e.g. employees, machines, etc.) while others are external (e.g. suppliers). This class is a generalization of the following classes (see the attributes of the class ComponentResource and its sub-classes in Table 11):

- ICT [class]: It represents elements enabling information exchanges inside enterprise system as well as in the P-S ecosystem.

- Human [class]: It represents people involved with different roles in the provision of the P-S.

- PhysicalEntity [class]: It represents physical means involved in the P-S development.

Table 11. ComponentResource attributes and its sub-classes

\begin{tabular}{|c|c|}
\hline Attribute & Description \\
\hline \multicolumn{2}{|l|}{ ComponentResource } \\
\hline affiliation & The owner (in case of property) or the employer (in case of Human) of the specific component. \\
\hline function & The tasks a component has to perform in the provision of a Product-Service. \\
\hline costPriceValue & several concepts about production cost, salary, price or the value of the component in PSS. \\
\hline \multicolumn{2}{|c|}{ Human [ComponentResource] } \\
\hline type & (1) person or (2) team, i.e. a single employee or a group of workers acting as a whole. \\
\hline Profile & Details of the person, such as his/her role, responsibilities, activities, seniority and experiences. \\
\hline skillAndCompetence & The capabilities of the human resource. \\
\hline \multicolumn{2}{|c|}{ ICT [ComponentResource] } \\
\hline type & The category of the component: (1) data, (2) software and (3) hardware. \\
\hline \multicolumn{2}{|c|}{ PhysicalEntity [ComponentResource] } \\
\hline type & The category of the component: (1) material, (2) tool and (3) machinery. \\
\hline
\end{tabular}

Decision [class]: It consists of actions defined for controlling processes, thus ensuring their proper running. Decisions are made based on the value of certain indicators or on other information coming from activities. The attributes of this class are described below (see Table 12).

Table 12. Decision attributes

\begin{tabular}{ll}
\hline Attribute & Description \\
\hline description & $\begin{array}{l}\text { The list of actions to be implemented following the decision. It can include time, responsibilities } \\
\text { and procedures. } \\
\text { The scope of the decision in terms of horizon, namely the timespan interested by a decision. Three } \\
\text { levels are identified: (1) Strategical, (2) Tactical or (3) Operational. }\end{array}$ \\
\hline
\end{tabular}

PI (Performance Indicator) [class]: It evaluates to what extent the objectives (of processes or stakeholders) are reached using the resources [class]. See the attributes of this class in Table 13.

Table 13. PI attributes

\begin{tabular}{ll}
\hline Attribute & Description \\
\hline description & $\begin{array}{l}\text { Detailed description of the PI, providing information about formulas, input data and link with } \\
\text { objective and drivers. }\end{array}$ \\
period & The interval after that the PI is (re)measured to find potential deviation from the target value. \\
measuredValue & PI value resulting from the monitoring system. \\
target & PI expected or desired value. \\
threshold & Acceptable PI value. \\
\hline
\end{tabular}


413

414

415

416

417

418

419

420

421

422

423

424

\section{Case study}

Having developed the PSS Conceptual Model (PSS-CM), the research methodology (see Figure 5) was pursued at its final step to perform a preliminary validation and to illustrate the results (see Figure 5). First, the structure of the model and the concept definitions were discussed during the research project, among the domain experts, from both academic and industrial perspectives. In addition, a case-study was performed, on one hand, to demonstrate PSS-CM instantiation while providing examples of concepts' instances from real business data, and on the other hand, to perform an initial evaluation of PSS-CM usage in business environment focused on servitization. Indeed, case study can be a preferred research strategy since "how" or "why" questions are being posed [74]. The adapted type in this context was a descriptive / exploratory case study (see case study categories in [74]).

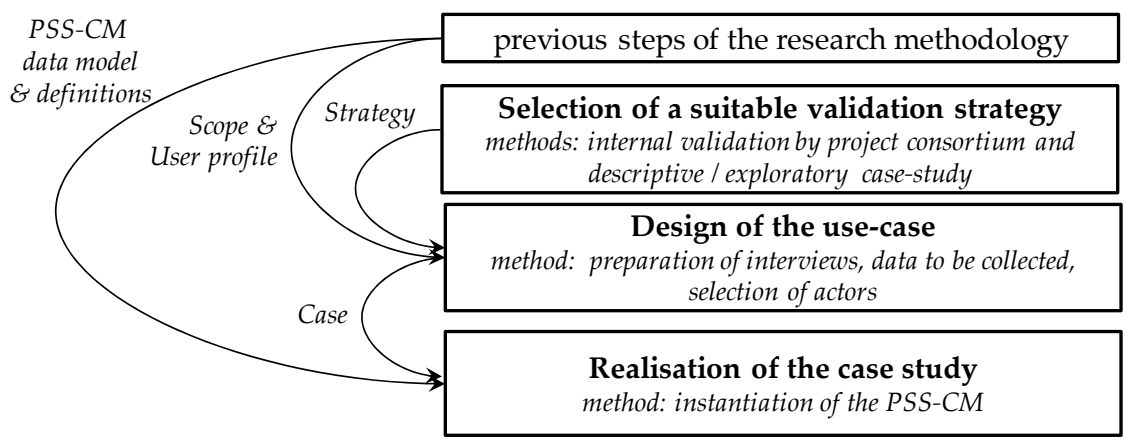

Figure 5. Case study methodology

\subsection{Design of the use-case}

The use-case was designed in relation to an enterprise which follows a servitization strategy. First, the scope and profile of the user in the enterprise were verified; data to be collected were defined; and a data collection method was stablished. Regarding the scope, the use-case can be positioned in the early stage of servitization where PSS ideas are presented to the enterprise management for approval. The actors involved in the case study were the business consultant and the engineer of the enterprise working on the design of a PSS and its development process. The objective of using PSS-CM by the enterprise was to achieve a common and global understanding on the main known / new concepts and their relationships which are necessary for defining a PSS and setup of an efficient development process.

The case study was conducted through interviews with the aforementioned actors and usage of company records as sources of information. Based on collected data, a model of PSS-CM was instantiated in its modeling environment. The model was validated by the enterprise actors through several iterations to reach a common agreement on the PSS concepts and definitions.

The modelled PSS is as part of a Cabin Video Surveillance System. It involves hardware, platform, and software applications, playing the role of the product [see product concept in PSS-CM], used for recording video data and providing various video analysis services [see service concept in PSS-CM]. Before detailing the instantiation of the PSS-CM, the PSS under study is globally illustrated in Figure 6 as an actigram. In this Figure:

- Connectors, represented as ovals, are objects exchanging entities (e.g. information or physical) with the PSS.

- Human, Physical or IT Resources, supporting the PSS, are represented by different icons below the activity.

- Flows, represented by arrows, indicate inputs (on the left), outputs (on the right), controls (on top), and supporting roles, skills or function of resources (on the bottom). 


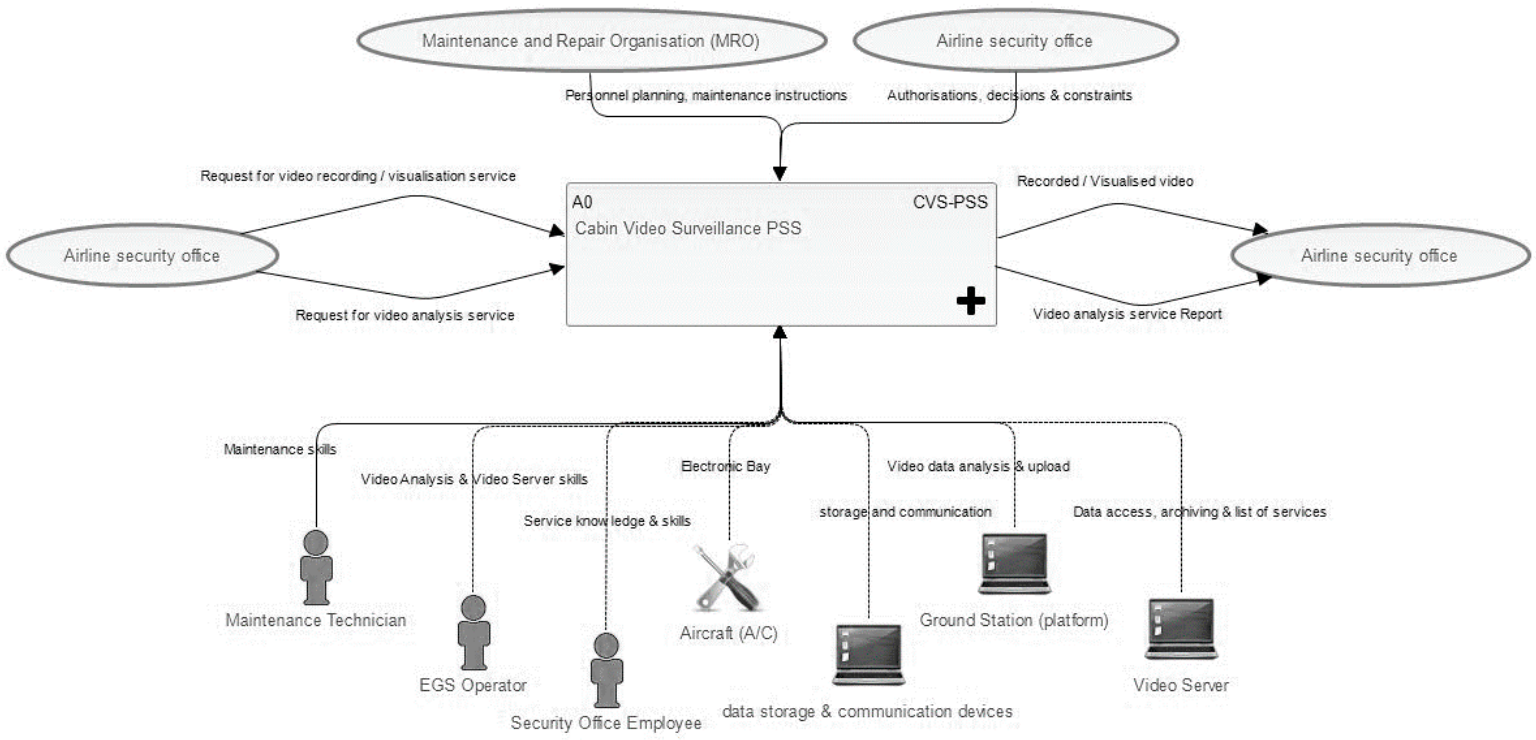

Figure 6. Cabin video surveillance PSS

\subsection{Instantiation of PSS-CM}

The PSS-CM was instantiated with the data from the enterprise and information provided by the interviewed actors. It should be noted that the instantiated model presented here does not include all the use-case data since the objective is to illustrate only one instance of each concept (i.e. classes, including their attributes and associations).

The instantiation of the PSS-CM was performed in Eclipse environment [73]. It was started by creating a "dynamic instance" of the PSS Conceptual Model and was continued by collecting the necessary information about the PSS such as stakeholders, processes and activities, resources, and the products and services while verifying the coherence of the proposed definitions with the definitions used in the enterprise. This was performed based on the information provided by the enterprise or using expert knowledge.

To complete the generated model (the XMI file), first two main classes were created as parts of the Ecosystem which is the root (see Figure B1 in Appendix B):

- The Ecosystem has a composition association includesEnterpriseSystem with the following stakeholders in the PSS ecosystem: Stakeholder Use-case (company providing the Cabin Video Surveillance System), Stakeholder MRO (Maintenance and Repair Organization), Stakeholder Aviation authorities, and Stakeholder Airline (Customer)

- The Ecosystem has composition association providesPS with Stakeholder. This indicates that the Ecosystem is formed around a ProductService which is the "Video Surveillance System".

Other classes were then created as parts of the Stakeholder and ProductService classes (see Figure B2 in Appendix B).

Following the above tasks in a hierarchical way, all the classes were added to the model until reaching at least one instance (example) of each concept. An excerpt of the model is illustrated in Figure B3 (see Appendix B). Then, for each class instance, the properties (i.e. attributes and associations) were quantified.

An example is illustrated in the Figure B4 (see Appendix B) for the class "Stakeholder use-case". After adding all the class instances and their properties to the model, its syntax (e.g. availability of obligatory attribute values, cardinalities, etc.) was verified. This functionality is available in an automatic way for the models developed in Eclipse environment. Such verification ensures the conformity of the instantiated model with the syntax of PSS Conceptual Model that plays the role of the meta-model. 


\section{Discussion and conclusions}

In this research work, the main objective was to provide conceptual propositions to researchers working in PSS context, and enterprise managers or designers involved with the early stages of servitization / productization. The propositions are mainly formulated around a conceptualization approach and its result called PSS Conceptual Model (PSS-CM). The contributions allow reducing the conceptual gaps of the managers through instantiation of this model and its components in their environment according to the proposed definitions. It should be mentioned that PSS-CM is presented as a class diagram and is formalized based on Ecore meta-mode.

The conceptualization approach behind the PSS-CM is founded on the fact that facing strategical decisions involved with new subjects, such as servitization, managers require abstract and simplified models with clear structures and a high ratio of known concepts. First to form the core of PPS-CM, the concept of PSS was studied from a systemic point of view since it inherits the intrinsic characteristics of a system. This core mainly includes concepts such as process, activity, resources, decision, performance indicator, etc. This allows increasing the comprehensibility of the model for its user starting by such known and generic concepts. Then, the first layer of PSS-CM was formed based on the analysis of product related and service related concepts in a separate way. For the second layer, several PSS definitions, classifications and viewpoints addressing PSS as a whole, were studied to gradually add specific PSS concepts and their attributes to the conceptual model.

To define / understand a PSS using PSS-CM, a top down approach can be followed. It is mainly critical to first reach a common understanding on the new concepts (e.g. product-service and its attributes) and their association with more known concepts (e.g. activity, resource etc.). In other words, the results of PSS conceptualization approach are followed in reverse from the upper layer (PSS-specific concepts) to the core (system concepts) of the model.

PSS-CM is developed in an open source modeling environment. Therefore, it can be easily used and integrated in the enterprises, particularly SMEs. Considering the complexity of each industrial environment, the model can be even customized (e.g. by adding new concepts or modifying the concepts' properties) according to the specific characteristics of the enterprise.

For validation purposes, the results were discussed in several iterations with research and industrial experts in the frame of a European research project called PSYMBIOSYS. This allowed ensuring a preliminary validation within the project consortium as a pilot community which should be then extended. Moreover, to verify the applicability and syntax of the model, a case study was performed with real data of an enterprise working on a servitization project. The user confirmed that the PSS-CM can be accepted and applied in their environment and the main advantage is considered to be its limited number of concepts while allowing reaching a common understanding on both known concepts and new concepts necessary for defining their PSS.

Regarding the future work, PSS-CM should be validated in a larger community of experts to improve the results for future exploitation. Therefore, it will be proposed to the European PSS cluster. Moreover, new instances can be created through additional industrial case studies to enrich the conceptual model and to verify its applicability. Eventually, elements of the model can be enriched while moving towards a standard ontology. However, as mentioned in the introduction of this paper, the core characteristic of PSS-CM, which is its lucidity, should be preserved to increase the chances of adoption by managers, particularly at strategical levels.

Acknowledgments: This work was supported by the European Commission through PSYMBIOSYS project: Product-Service sYMBIOtic SYStems (H2020 FoF-05-2014, No. 636804). The costs to publish in open access are also covered by this funding body.

Author Contributions: All authors have contributed to the intellectual content of this paper. A. Pirayesh, Marco Seregni and G. Doumeingts designed and conducted the research, and proposed the structure of the conceptual model. A. Pirayesh defined the conceptualization approach. All authors contributed to the identification and definition of concepts. I. Westphal and C. Zanetti were mainly involved in the definition of business concepts. C. Hans was particularly involved in the case-study. All authors have read and approved the final manuscript.

Conflicts of Interest: The authors declare no conflict of interest. 


\section{7}

538

Table A1. Associations in PSS-CM

\begin{tabular}{|c|c|c|}
\hline Association & Cardinality & Description \\
\hline \multicolumn{3}{|l|}{ Ecosystem } \\
\hline includesStakeholder & $1 . .^{*}$ & Ecosystem is formed by one or several enterprises (class EnterpriseSystem) \\
\hline ProvidesPS & $1 . .^{*}$ & $\begin{array}{l}\text { An Ecosystem (or part of ecosystem) operations result in the provision of at least } \\
\text { one P-S. }\end{array}$ \\
\hline \multicolumn{3}{|l|}{ ProductService } \\
\hline consistsOfProduct & $1 . .^{*}$ & A P-S bundle comprises one or more physical products. \\
\hline consistsOfService & $1 . .^{*}$ & A P-S bundle comprises one or more services. \\
\hline isFormingPSSwith & $1 . .^{*}$ & $\begin{array}{l}\text { P-S is associated with Stakeholder. This association indicates the formation of a } \\
\text { PSS. }\end{array}$ \\
\hline \multicolumn{3}{|l|}{ Product } \\
\hline Generalization & - & $\begin{array}{l}\text { A product is considered a physical entity [component] which is the final physical } \\
\text { output provided by a stakeholder to the user. }\end{array}$ \\
\hline \multicolumn{3}{|r|}{ 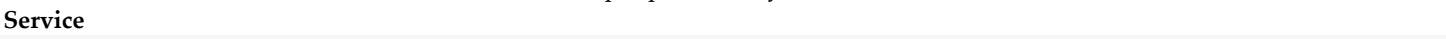 } \\
\hline involves Component & $1 . .^{*}$ & $\begin{array}{l}\text { A service can involve different type of components (e.g. physical product, human } \\
\text { as user or provider, IT tool as provider). }\end{array}$ \\
\hline \multicolumn{3}{|l|}{ Stakeholder } \\
\hline is AssessedByPI & $1 . .^{*}$ & $\begin{array}{l}\text { One or more global PIs are defined for monitoring and controlling stakeholder } \\
\text { performance. }\end{array}$ \\
\hline involvesDecision & $1 . .^{*}$ & $\begin{array}{l}\text { A stakeholder takes one or many decisions at different levels (strategical, tactical } \\
\text { and operational) to control its processes. }\end{array}$ \\
\hline consistsOfProcesses & $1 . .^{*}$ & $\begin{array}{l}\text { A stakeholder [of type enterprise] consists large number of processes, design, } \\
\text { manufacturing, delivery, planning. }\end{array}$ \\
\hline hasComponents & $1 . .^{*}$ & $\begin{array}{l}\text { A stakeholder [of type enterprise] comprises one or many entities (class } \\
\text { components), which can be of different types ICT, Human or Physical. }\end{array}$ \\
\hline \multicolumn{3}{|l|}{ Process } \\
\hline isComposedofActivity & $1 . .^{*}$ & $\begin{array}{l}\text { Processes are decomposed in one or more activities. Complex processes count } \\
\text { several activities. An elementary process can be decomposed in just one activity, } \\
\text { being the activity the process itself. }\end{array}$ \\
\hline \multicolumn{3}{|l|}{ Activity } \\
\hline Is ComposedOfActivity & $0 . .^{*}$ & $\begin{array}{l}\text { An activity can be decomposed into sub-activities. Atomic activities cannot be } \\
\text { further decomposed. }\end{array}$ \\
\hline hasComponent & $4 . .^{*}$ & $\begin{array}{l}\text { An activity is related to components with different roles: } \\
\text { An activity transforms one or more inputs into output(s) } \\
\text { For the transformation, an activity uses one or more components as resources } \\
\text { To be performed properly, the transformation requires controls, objectives and } \\
\text { constraints }\end{array}$ \\
\hline \multicolumn{3}{|l|}{ ComponentResource } \\
\hline isCoupledWithComponent & $0 . .^{*}$ & $\begin{array}{l}\text { A component can be associated with another component (e.g. a person using a } \\
\text { Tool) }\end{array}$ \\
\hline isComposedOfComponent & $0 . .^{*}$ & $\begin{array}{l}\text { A component might be composed of other components. For instance, a product } \\
\text { can be resulted from the assembly of different parts. }\end{array}$ \\
\hline \multicolumn{3}{|l|}{ ICT [component] } \\
\hline Generalization & n.a. & "ICT" class is a specialization (child) of "Component" (parent). \\
\hline \multicolumn{3}{|l|}{ Human [resource] } \\
\hline Generalization & n.a. & "Human" class is a specialization (child) of "Component" (parent). \\
\hline \multicolumn{3}{|c|}{ PhysicalEntity [component] } \\
\hline Specialization/Inheritance & n.a. & "PhysicalEntity" class is a specialization (child) of "Component" (parent). \\
\hline \multicolumn{3}{|l|}{ Decision } \\
\hline affectsProcess & $1 .{ }^{*}$ & $\begin{array}{l}\text { A decision, to be relevant, must influence at least one process in the company. } \\
\text { Some decisions, mainly at strategical level, have impact on several processes. }\end{array}$ \\
\hline isMadeByHuman & $1 . .^{*}$ & $\begin{array}{l}\text { A decision involves one or many decision-makers. Simple decision, in everyday } \\
\text { running at operational level, can be taken from single persona while strategical } \\
\text { decisions usually involve several people with different skills, competences and } \\
\text { roles. }\end{array}$ \\
\hline isSupportedByICT & $0 . .^{*}$ & A decision may (or not) be supported by one or several tools. \\
\hline \multicolumn{3}{|l|}{ PI } \\
\hline isLinkedToComponent & $1 . .^{*}$ & $\begin{array}{l}\text { A Performance Indicator (PI) can be linked to one or several components as the } \\
\text { driver of the PI. In this case, the component is intended to improve the PI value. }\end{array}$ \\
\hline
\end{tabular}


539

\section{Appendix B}

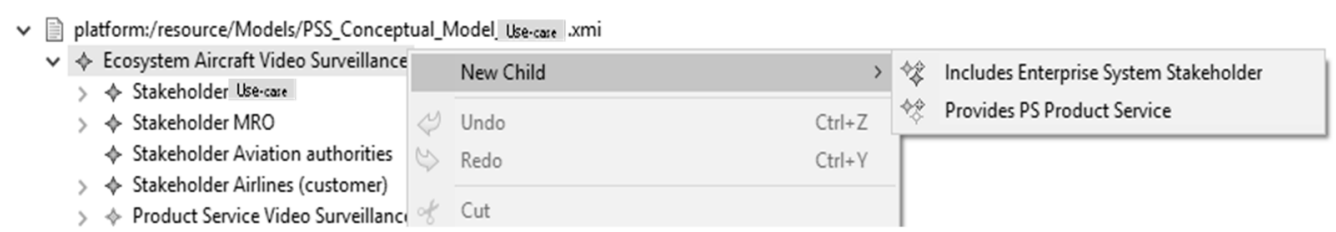

Figure B1. Creation of initial classes from the root for the use-case

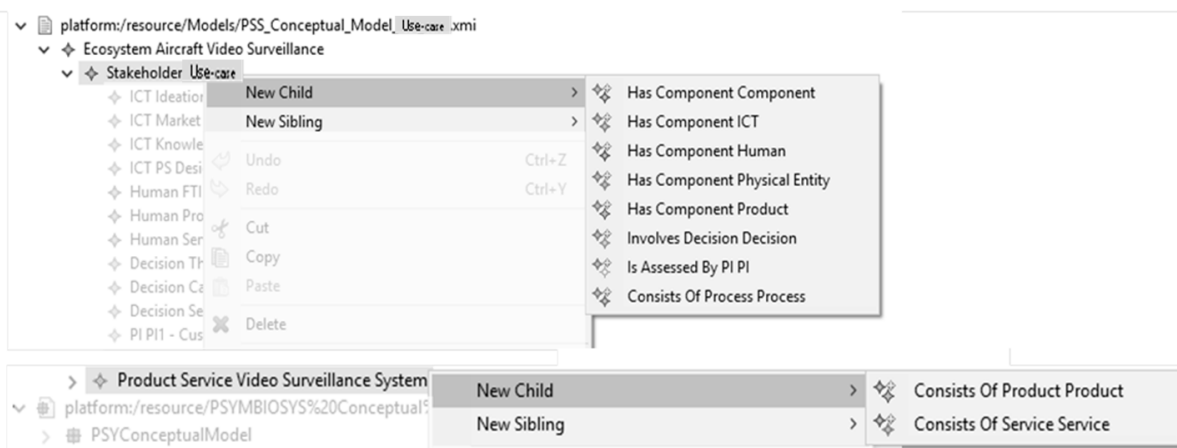

Figure B2. Creation of new classes to the two main classes of the model for the use-case

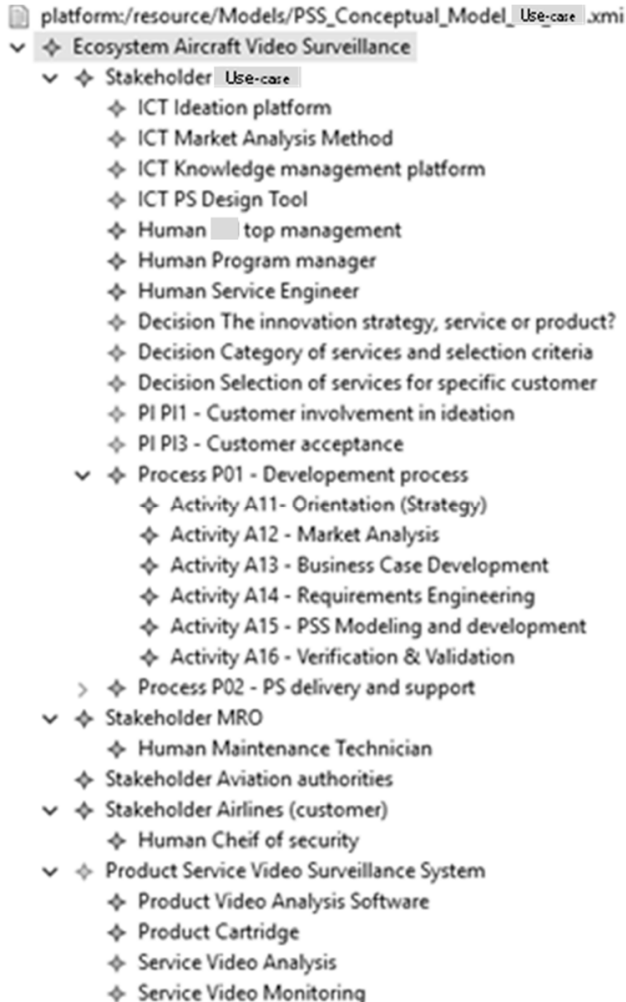

Figure B3. An excerpt of the instantiated PSS Conceptual Model for the use-case

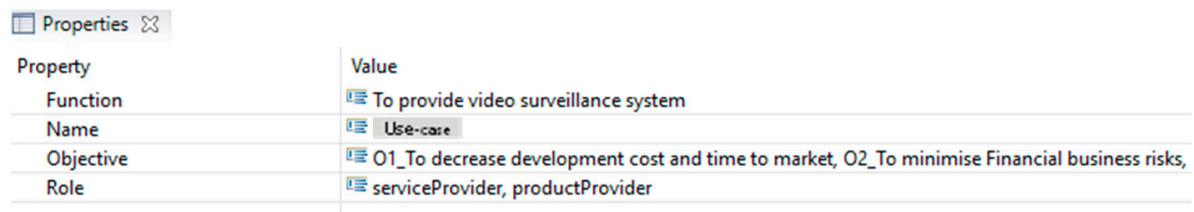

Figure B4. Properties of the class "Stakeholder" in the use-case 


\section{References}

1. Turunen, T.; M. Finne. The organisational environment's impact on the servitization. European Management Journal, 2014, 4(32), pp. 603-615.

2. Neely, A. The servitization of manufacturing: An analysis of global trends. Proceedings of 14th European Operations Management Association Conference, Ankara, Turkey, June 2007, pp. 1- 10.

3. Vandermerwe, S.; Rada J. Servitization of Business: Adding Value by Adding Services. European Management Journal, 1988, 6(4), pp. 314-324.

4. Briscoe, G.; Keränen K.; Parry G. Understanding complex service systems through different lenses: An overview. European Management Journal, 2012, 30, pp. 418-426.

5. Cavalieri, S.; Pezzotta G. \{Product-Service\} Systems Engineering: State of the art and research challenges. Comput. Ind., 2012, 63, pp. 278-288.

6. Sassanelli, C.; Pezzotta, G.; Rossi, M.; Terzi, S.; Cavalieri, S; Towards a Lean Product Service Systems (PSS) Design: state of the art, opportunities and challenges. in 7th CIRP IPSS Conference, Saint-Etienne, France, May 2015. Procedia CIRP, 2015, 30, pp. 191-196

7. Kim, S.; Son, C.; Yoon, B.; Park, Y. Development of an Innovation Model Based on a Service-Oriented Product Service System (PSS). Sustainability, 2015, 7(11), p. 14427-14449.

8. Lindberg, N.; Nordin F. From products to services and back again: Towards a new service procurement logic. Industrial Marketing Management, 2008, 37(3), pp. 292-300.

9. Oliveira, M.G.; Mendes G.H.S.; and Rozenfeld H. Bibliometric Analysis of Product-Service System Research Field. in 7th CIRP IPSS Conference. 2015. Saint-Etienne, France. Procedia CIRP, 2015, 30, pp. 114119

10. Tukker, A., Eight types of product-service system: eight ways to sustainability? Experiences from SusProNet. Business Strategy and the Environment, 2004, 13(4), Special Issue: Innovating for Sustainability, pp. 246-260.

11. ElMaraghy, W., et al., Complexity in engineering design and manufacturing. CIRP Annals - Manufacturing Technology, 2012, 61, p. 793-814.

12. Wiendahl, H. and P. Scholtissek, Management and Control of Complexity in Manufacturing. CIRP Annals - Manufacturing Technology, 1994, 43(2), pp. 533-540.

13. Pirayesh, A.; Doumeingts G. Symbiotic PSS development supported by Enterprise Modelling Techniques. in Enterprise Interoperability $\mathrm{n}$ the Digitized and Networked Factory of the Future, Proceedings of I-ESA' 16 conference - workshops. Guimarães, Portugal, 2016, Enterprise Interoperability in the Digitized and Networked Factory of the Future, Publisher: ISTE Ltd., London, United Kingdom, September 2016, pp. 227234. ISBN: 9781847040442.

14. Perona, M.; Saccani N.; Bacchetti A., Research vs. Practice on Manufacturing Firms' Servitization Strategies: A Gap Analysis and Research Agenda. Systems, 2017, 5(1), p. 19.

15. Gebauer, H.; Fleisch E.; Friedli T.; Overcoming the service paradox in manufacturing companies. European Management Journal, 2005, 23(1), pp. 14-26.

16. Zacharewicz, G.; Pirayesh-Neghab, A.; Seregni, M.; Ducq, Y.; Doumeingts, G. Simulation-Based Enterprise Management; Model Driven from Business Process to Simulation, in Guide to Simulation-Based Disciplines. 2017; Editors: Mittal, S., Durak, U., Ören, T., Eds.; Publisher: Springer International Publishing AG, Cham, Switzerland, 2017, pp. 261-289. ISBN: 978-3-319-61263-8.

17. Idrissi, N.A., X. Boucher, and K. Medini, Generic conceptual model to support PSS design processes. Procedia CIRP, 2017, 64, pp. 235-240.

18. Lee, J.; Chae, H.; Kim, C-H.; Kim, K. Design of product ontology architecture for collaborative enterprises. Journal of Expert Systems with Applications, 2009, 36, pp. 2300-2309.

19. Lezoche, M.; Panetto H.; Aubry A. Conceptualisation approach for cooperative information systems interoperability. in ACM. 13th International Conference on Enterprise Information Systems (ICEIS), June 2011, Beijing, China, 2011, pp.101-110.

20. Karray, M.H. Contribution à la spécification et à l'élaboration d'une plateforme de maintenance orientée connaissances (in French), PhD Thesis, University of Franche-Comté, Franche-Comté, France, 2012.

21. Annarelli, A.; Battistella C.; Nonino F. Product service system: A conceptual framework from a systematic review, Journal of Cleaner Production, 2016, 139, pp. 1011-1032. 
22. Lahya, A.; Found P. Developing a conceptual framework for PSS business models. Proceedings of the 9th CIRP IPSS Conference: Circular Perspectives on Product/Service-Systems, Copenhagen, Denmark, June 2017, Procedia CIRP, 2017, 64, pp. 91-96.

23. Ducq, Y.; Agostinho, C.; Chen, D.; Zacharewicz, G.; Jardim-Goncalves, R.; Doumeingts, G. Generic Methodology for Service Engineering based on Service Modelling and Model Transformation State of the art in model driven approaches and model transformation, in MSEE book: Manufacturing Service Ecosystem: Achievements of the European 7th Framework Programme FoF-ICT Project MSEE: Manufacturing SErvice Ecosystem (Grant No.284860). Publisher: Bremer Schriften zur integrierten Produkt- und Prozessentwicklung, Aachen: Verlag-Mainz, Germany, 2014, pp. 41-49.

24. Aurich, J.C.; Fuchs C.; Wagenknecht C., Life cycle oriented design of technical product-service systems. Journal of Cleaner Production, 2006, 14(17), pp. 1480-1494.

25. Yang, L.; Xing K.; Lee S.H. Framework for PSS from service perspective. Proceedings of the International MultiConference of Engineers and Computer Scientists, IMECS'10, vol. 3, Hong Kong, 2010, pp. 1656-1661.

26. Sakao, T.; Shimomura Y. Service engineering: a novel engineering discipline for producers to increase value combining service and product, Journal of Cleaner Production, 2007, 15(6), pp. 590-604.

27. Sakao, T., et al., Computer aided design model-ing design objects in CAD system for service/product engineering. Computer-Aided Desig, 2009, 41(3), p. 197-213.

28. Bell, M., Service-Oriented Modelling: Service Analysis, Design and Architecture. Publisher: John Wiley and Sons, Incorporated, Hoboken, New Jersey, United States, 2008. ISBN: 978-0-470-14111-3.

29. Abramovici, M.; Neobach, M.; Schulze, M.; Spura, C. Metadata Reference Model for IPS2 Lifecycle Management. in Proceedings of the 1st CIRP Industrial Product-Service Systems (IPS2) Conference, Cranfield, UK, April 2009. pp. 268-272.

30. Hara, T.; Arai, T.; Shimomura, Y.; Sakao, T. Service CAD system to integrate product and human activity for total value. CIRP Journal of Manufacturing Science and Technology, 2009, 1(4), p. 262-271.

31. Geum, Y.; Park Y., Designing the sustainable producteservice integration: a producte-service blueprint approach. Journal of Cleaner Production, 2011, 19(14), pp. 1601-1614.

32. Müller, P.; Schulz F.; Stark R. Guideline to elicit requirements on industrial product-service systems. in Proceedings of 2nd CIRP International Conference on Industrial Product/Service Systems. Linköping, Sweden, April 2010, pp.109-116.

33. W3C, Service Modeling Language, Version 1.1., World Wide Web Consortium (W3C), 2009.

34. Van Ostaeyen, J.; Van Horenbeek, A.; Pintelon, L.; Duflou, J. R., A refined typology of product-service systems based on functional hierarchy modelling. Journal of Cleaner Production, 2013, 51, pp. 261 - 276.

35. Wiesner, S.; Padrock P.; and Thoben K.-D. Extended Product Business Model development in four manufacturing case studies. proceedings of the 6th CIRP Conference on Industrial Product-Service Systems Procedia CIRP, 2014, 16, pp. 110-115.

36. Trevisan L.; Brissaud D. Engineering models to support product-service system integrated design. CIRP Journal of Manufacturing Science and Technology, 2016, 15, pp. 3-18.

37. Le Moigne, J. L. La théorie du système général, Théorie de la modélisation (in French), Publisher: Presses universitaires de France, Paris, France, 1977.

38. Simon, H., The Sciences of the Artificial. 1969, Cambridge: MIT Press.

39. Mesarovic, M.D., D. Masko, and Y. Takahara, Theory of Hierarchical Multilevel Systems. 1970, New York and London: Academic Press.

40. Doumeingts, G., La méthode GRAI: Methode de Conception des Systemes en Productique (in French), PhD thesis, University of Bordeaux 1, Bordeaux, France, 1984.

41. Chen, D.; Doumeingts G. The GRAI-GIM reference model, architecture and methodology, in Architectures for Enterprise Integration, Bernus, P. Nemes, L. Williams, T. J., Eds. Publisher: Springer, Boston, MA, United States, 1996, pp. 102-126. ISBN 978-1-4757-4541-2

42. CEN, Quality management systems-requirements (DIN EN ISO 9001:2008), Comité Européen de Normalisation (English: European Committee for Standardization), 2008.

43. Wuest, T., Identifying Product and Process State Drivers in Manufacturing Systems Using Supervised Machine Learning. Publisher: Springer International Publishing, 2015. ISBN 978-3-319-17610-9

44. Korndörfer, W., Allgemeine Betriebswirtschaftslehre: Aufbau - Ablauf - Führung - Leitung (in German: General Business Studies: Structure - Process - Leadership - Management). Publisher: Gabler Verlag., 2003. ISBN 978-3-409-12048-7. 
45. Porter, M.E., On competition. Publisher: Harvard Business Press. Boston, 2008.

46. Todd R. H.; Allen D. K.; Alting L.; Fundamental Principles of Manufacturing Processes, Publisher: Industrial Press Inc., United States, 1994, ISBN: 978-0-831-13050-3.

47. MSEE, Deliverable D11.1, Service concepts, models and method: Model Driven Service Engineering, European 7th Framework Programme FoF-ICT Project MSEE: Manufacturing SErvice Ecosystem (Grant No.284860), 2012.

48. Callon, M.; Meadel C.; Rabeharisoa V., The economy of qualities. Economy and Society, 2002, 2(31), pp. 194-217.

49. Chesbrough, H., Open Service Innovation: Rethinking your Business to Grow and Compete in a New Era, Publisher: Jossey-Bass John Wiley \& Sons, 2011, San Francisco, CA, 2011; ISBN: 978-0-470-90574-6

50. Spohrer, J.; Maglio P. Toward a Science of Service Systems, in Handbook of Service Science. Service Science: Research and Innovations in the Service Economy, Maglio P., Kieliszewski C., Spohrer J., Eds., Publisher: Springer, Boston, MA, 2010; ISBN: 978-1-4419-1627-3

51. Andersen, J. B.; McAloone, T. C.; Mateu, G. i A.; Mougaard, K.; Neugebauer, L.; Hsuan, J.; Ahm, T, PSS Business Models: A workbook in the PROTEUS series, Publisher: Technical University of Denmark, 2013; ISBN: 978-87-90416-93-5.

52. Goedkoop, M.; van Haler, C.; te Riele, H.; Rommers, P. Product Service-Systems, ecological and economic basics. Report for Dutch Ministries of Environment (VROM) and Economic Affairs (EZ). 1999.

53. Mont, O., Drivers and barriers for shifting towards more service-oriented businesses: Analysis of the \{PSS\} field and contributions from Sweden. J. Sustain. Prod. Des., 2002, 2, pp. 89-103.

54. Manzini, E.; Vezzoli, C. A strategic design approach to develop sustainable product service systems: examples taken from the 'environmentally friendly innovation' Italian prize. Journal of Cleaner Production, 2003, 11(8), pp. 851-857.

55. Baines, T. S.; Lightfoot, H. W.; Evans, S.; Neely, A.; Greenough, R.; Peppard, J.; Wilson, H. State-of-the-art in product-service systems. Proceedings of the Institution of Mechanical Engineers, Part B: Journal of Engineering Manufacture, 2007, 221(10), pp. 1543-1552.

56. Charter, M.; Adams G.; Clark T., Product Services in the need area 'Information and Communication SusProNet final report, The Centre For Sustainable Design, 2004.

57. Roy, R. Sustainable product-service systems. Futures, 2000, 32(3), pp. 289-299.

58. Thoben, K.-D.; Jagdev H.; Eschenbächer J. Extended Products: evolving traditional product concepts. in Proceedings of the 7th International Conference on Concurrent Enterprising: Engineering the Knowledge Economy through Co-operation, Bremen, Germany, 2001.

59. Meier, H.; Völker O; Funke B. Industrial Product-Service Systems (IPS2): Paradigm shift by mutually determined products and services. International Journal of Advanced Manufacturing Technology, 2011, 52, pp. 1175-1191.

60. Park, Y.; Geum Y.; Lee H. Toward integration of products and services: Taxonomy and typology. Journal of Engineering and Technology Management, 2012, 29(4), pp. 528-545.

61. Zancul, E.d.S.; Takey, S.M.; Barquet, A.P.B.; Kuwabara, L.H.; Miguel, P.A.C.; Rozenfeld, H. Business process support for IoT based product-service systems (PSS), Business Process Management Journal, 2016, 22(2), pp. 305-323.

62. Pardo, R.J.H.; Bhamra T.; Bhamra R. Sustainable Product Service Systems in Small and Medium Enterprises (SMEs): Opportunities in the Leather Manufacturing Industry, Sustainability, 2012, 4(2), pp. 175-192.

63. PSYMBIOSYS, Deliverable D7.6 - Symbiotic Innovation in P-S Ecosystems, PSYMBIOSYS: Product-Service sYMBIOtic SYStems (H2020 FoF-05-2014, No. 636804), 2017.

64. Vargo, S.L.; Maglio P.P.; Akaka M.A.; On value and value co-creation: A service systems and service logic perspective, European Management Journal, 2008, 26(3), pp. 145-152.

65. Barnett, N. J.; Parry, G.; Saad, M.; Newnes, L. B.; Goh, Y.M. Servitization: Is a Paradigm Shift in the Business Model and Service Enterprise Required?, Strateg. Chang., 2013, 22, pp. 145-156.

66. Visnjic Kastalli, I.; Van Looy B. Servitization: Disentangling the Impact of Service Business Model Innovation on Manufacturing Firm Performance, Journal of Operations Management, 2013, 31(4), pp. 169-180.

67. Turunen, T.; Neely A. Organising servitization: an in-depth case study, Working Paper, University of Cambridge 2012. 
68. Wiesner, S.; Freitag, M.; Westphal, I.; Thoben, K.-D. Interactions between Service and Product Lifecycle Management. in Proceedings of the 7th CIRP Industrial Product-Service Systems (IPS2) Conference, St. Etienne, France, June 2015, Procedia CIRP, 2015, 30, pp. 36-41.

69. Westphal, I.; Freitag M.; Thoben K.-D. Visualization of Interactions Between Product and Service Lifecycle Management, in Advances in Production Management Systems: Innovative Production Management Towards Sustainable Growth, Umeda S., Nakano M., Mizuyama H., Hibino H., Kiritsis D., von Cieminski G., Eds., Publisher: Springer, Champ, 2015, p. 575-582.

70. Wiesner, S.; Thoben k-D. Cyber-Physical Product-Service Systems, in Multi-Disciplinary Engineering for Cyber-Physical Production Systems, Biffl S., Lüder A., Gerhard D., Eds., Springer, Cham., 2017, p. 63-88.

71. Pirayesh, A.; Etienne A.; Kleiner M.; Roucoules L.; Performance evaluation of collaboration in the design process: Using interoperability measurement. Computers in Industry, 2015, 72, pp. 14-26.

72. Freitag, M.; Schiller C. Approach to Test a Product-Service System During Service Engineering. Procedia CIRP, 2017, 64, p. 336-339.

73. Eclipse, Eclipse Modeling Tools, Version: Mars 2 Release (4.5.2). 2017.

74. Yin, R.K. Case Study Research. Design and Methods. 5th ed., Publisher: SAGE Publications, 2013. 